\title{
A Tiny Adventure: the introduction of problem based learning in an undergraduate chemistry course
}

\author{
Dylan P. Williams ${ }^{a}$, Jonathan R. Woodward ${ }^{b}$, Sarah L. Symons ${ }^{c}$ and David L. Davies ${ }^{a}$
}

Received 22nd June 2009, Accepted 11th November 2009

DOI: $10.1039 / \mathrm{C} 001045 \mathrm{~F}$

Year 1 of the chemistry degree at the University of Leicester has been significantly changed by the integration of a problem based learning (PBL) component into the introductory inorganic/physical chemistry module, “Chemical Principles”. Small groups of 5-6 students were given a series of problems with real world scenarios and were then given the responsibility of planning, researching and constructing solutions to the problem on a group wiki hosted on the Universty's Virtual Learning Environment (VLE). The introduction of PBL to the course was evaluated both quantitatively and qualitatively. Class test and exam results were analysed and compared with those achieved in previous years (i.e. before the introduction of PBL). It was found that student performance was at least as good as it had been before the introduction of PBL. Retention figures after PBL had risen sharply (not one PBL student dropped out of the course during the first term). Student and staff feedback was also collected for qualitative analysis of the impact of the change. Combining these findings showed that students appeared to show an improvement in, and recognition of the acquisition of, transferable skills and that group work on immediate arrival at university (representing an opportunity to use social skills within an academic exercise) led to high student retention within the PBL cohort.

Keywords: problem based learning, group work, mini-projects, transferable skills, wiki, chemistry, projects

\section{Introduction and motivation}

We describe here the introduction of Problem-Based Learning (PBL) into the undergraduate chemistry program at the University of Leicester. Recent years have seen changes in the type of students studying chemistry degrees and their motivation for study. This is due to a number of factors including a greater recent emphasis on widening participation programmes which has increased student recruitment from underrepresented demographics (Walker, 2009). There were two primary drivers for the introduction of PBL into the first year undergraduate degree course. The first was to examine its effect on student motivation in an attempt to foster greater levels of intrinsic motivation for chemistry study in new students. Previous studies have shown that PBL approaches can result in increased student motivation (Bredderman, 1983; Barrows, 1986; Blumenfeld et al., 1991). The second was based on a concern about students' increasing demand [or expectation] to know precisely what they are required to learn rather than reading around the subject and taking responsibility for their own learning, and so becoming independent learners. Clearly these two factors are closely

\footnotetext{
${ }^{a}$ Department of Chemistry, University of Leicester, University Road, Leicester, United Kingdom, LE1 7RH. E-mail: dpw10@le.ac.uk

${ }^{b}$ Chemical Resources Laboratory Tokyo Institute of Technology 4259

Nagatsuta, Midori-ku Yokohama 226-8503, Japan.

E-mail: jonnywoodward@ipo.titech.ac.jp

${ }^{c}$ Integrated Science Program and Department of Physics and Astronomy, McMaster University, 1280 Main Street West, Hamilton, Ontario, L8S 4L8, Canada.E-mail:symonss@mcmaster.ca
}

related, and it was hoped that PBL might start to break up the 'spoon-feeding' habits that many students have now developed quite strongly from their previous studies.

Thus, although student performance was of importance, this was not the driving force for the PBL approach. Clearly, any negative impact of the introduction of PBL is to be avoided, but equally, the primary goals of the program were not higher exam marks. Key indicators of success would lie in increased student motivation and understanding of their role, potential and responsibility as undergraduates. To this end, the PBL component was designed so that data from previous years' performance could be directly compared. More importantly, from the outset extensive measures were taken to allow detailed monitoring of student and staff perceptions and attitudes. In addition to this, the impact of the introduction of PBL on staff was monitored, as well as the ease of transition for the department from a completely traditional course to one which incorporated PBL.

It was decided that PBL would be introduced to the core Physical/Inorganic Level 1 module (Chemical Principles, $\mathrm{CH} 1000)$. This covers some of the fundamental concepts introduced at the start of many chemistry degrees, including size and scale, atomic and molecular structure, chemical bonding, stereochemistry and spectroscopy. These areas include some topics that lend themselves well to real-world problems (for example spectroscopic analysis) and others that are particularly abstract (e.g. quantisation, hybridisation). The department was fortunate to have staff members experienced in the teaching of these abstract concepts, but who had also 
developed content for and participated in the development, introduction and teaching of the Interdisciplinary Science degree at Leicester, which is taught entirely by PBL? In addition, another motivation for the PBL approach was to take the opportunity to try to draw together ideas from the traditionally separate Physical/Inorganic and Organic modules. Compartmentalisation of ideas is another problem (Andraos, 1999) that has worsened in recent years, and it was hoped that by suitably designed problems the students would mix 'organic' and 'physical' chemical ideas together, and break down the artificial barriers between them that are an undesirable side effect of the way the subject is divided for teaching to undergraduates.

The Department of Chemistry at Leicester became a project partner of Chemistry for our Future (Strand 3.2), a two year programme funded by the Higher Education Funding Council for England and managed by the RSC ${ }^{\ddagger}$. As a project partner, the department received funding that allowed the appointment of an 'Educational Developer' responsible for the development of PBL material. PBL resources were developed during summer 2007 for implementation in the 2007/08 and 2008/09 academic years. A series of PBL problems were developed over the summer; some of these problems were based on the 'Science of the Invisible' module, taught as part of the University of Leicester's Interdisciplinary Science (iScience) degree programme. Problems used in the i-Science version were substantially adapted for use in the Chemistry degree in order to integrate with the exisiting lecture content of the chemistry module. In addition to these problems some entirely new PBL content was developed for the module focusing on the general theme of spectroscopy. There had been a departmental desire to see more general spectroscopy in the first year modules and it was thought that an excellent way to introduce it would be through PBL.

\section{Background}

PBL is an educational technique that has been previously described as "an instructional strategy in which students confront conceptually ill-structured problems and strive to find meaningful solutions" (Rhem, 1998). The earliest documented use of PBL was in the training of physicians at McMaster University, Ontario in the late 1960s (Woods, 1996; Boud et al., 1998). PBL is now used in many institutions across the world in a range of subject areas, including chemistry (Duch et al., 2001). Other institutions have adopted PBL approaches in chemistry teaching over the past decade include the Universities of Hull and Plymouth (Belt et al., 2002).

A good PBL activity engages students by encouraging them to work together with members of their group (Boud and Feletti, 1997; Harris et al, 2006) on solutions to a number of complex problems set in real-world scenarios. PBL problems can also be written in a way that give students the opportunity to make connections between different subject areas that had previously seemed separate (Raine and Symons, 2005). PBL problems also allow students to improve interpersonal and communication skills (Engel, 1997).

There have been several reported benefits of using PBL in
University level teaching, including greater student engagement (Bredderman, 1983; Barrows, 1986 and Blumenfeld et al., 1991), the reinforcement of concepts taught using traditional techniques, student application of knowledge to realistic scenarios and the development of transferable skills (such as communication, interpersonal and organisational skills) (Woods, 1996). Several limitations of the approach have also been reported, including the fact that PBL can be resource intensive (Heycox and Bolzan, 1991) and the possibility that students can face an excessive workload or have insufficient time to cover the learning issues in sufficient depth if the problem has not been constructed carefully (Albanese and Mitchell, 1993, and Ryan, 1997). It was vital that these issues were identified at the development stage.

\section{Implementation}

\section{Structure}

'Chemical Principles' is a core module in level 1 of the Chemistry degree (MChem/BSc) programme at the University of Leicester. In previous years it has been taught through a combination of lectures (28 lectures and 1 revision lecture), workshops (4 sessions), underlying workshops (6 sessions that were based around related background science), maths sessions (10 workshops and 10 lectures), tutorials (4 sessions) as well as 2 Multiple Choice Question (MCQ) tests. In the 2007-08 academic year PBL was introduced to the module, which resulted in the overall module structure changing to 20 lectures (plus 1 revision lecture), 3 workshops, 18 PBL sessions (these were one hour sessions in which the groups had to meet each other, and staff or postgraduate facilitators were also available to ensure that groups were progressing) and a lecture introducing the PBL method. PBL sessions were facilitated by graduate students, the Educational Developer and a member of the academic staff. The overall workload of the member of the academic staff was approximately the same as it had been in previous years, but graduate students were used to facilitate the PBL sessions. The ratio of $\mathrm{PBL}$ facilitator: students was approximately 1:14 compared with a ratio of about 1:20 (academic staff: undergraduate students) in the previously used underlying workshops The underlying workshops were removed and the majority of their resources were integrated into the PBL component of the module. The maths component of 'Chemical Principles' was unaffected by the introduction of PBL. In the 2007/08 academic year, 84 students took this module.

\section{Introduction of problems to students}

Content was introduced to students using lectures and tutorials, PBL activities were used to develop on themes introduced during the lectures. The problems required students to do additional research, which built on what had been introduced in lectures. Often, PBL problems followed lectures on related topics, but occasionally, content was covered in PBL problems first.

Students were introduced to PBL in a short introductory lecture at the start of their first week in the Department; this 
included a summary of the PBL concept and some basic guidance on how to use the necessary parts of the Virtual Learning Environment (VLE) for this module. The first PBL problem was made available to students by email and on Blackboard, the University's VLE, later in the week. In the introductory session students were introduced to the scenario that was used for the first six problems, 'A Tiny Adventure' (For an example of the first of these problems please refer to the Appendix). In the context of this scenario students were asked to act as scientific advisors to a Hollywood production team working on a new science-fact-based blockbuster movie. The scenario consisted of six problems; each problem was issued on a Thursday afternoon and lasted one week. The first contact session for each problem was the afternoon after the release of the problem. Students were split into 17 groups (of 5 or 6 students) for the PBL contact sessions (this allowed a staff:student ratio of approximately 1:14), these groups were assigned according to degree registration (i.e. all Forensic Science students were kept in groups together). The group size was based on previous applications of PBL in physical science teaching (Woods, 1996; Raine and Symons, 2005). The groups were assigned names corresponding to seventeen chemical elements. Due to the demands on teaching space the students had to be divided up into two teaching areas. By assigning groups as 'metallic' and 'non-metallic' elements based on teaching area, many problems with navigation and lost students were avoided at the start of term.

\section{Implementation in the classroom}

There were two PBL contact sessions per week; the first on the Friday afternoon and the second on the Tuesday morning. The first contact session of the semester was opened with a short icebreaker, which allowed all the group members to introduce themselves to the people they would be working with for the next nine weeks. After the students had introduced themselves, they were asked to focus on the problem. In order to help the students to start thinking about the problem, they were advised to follow a simple strategy, 'SET', designed specifically for this activity (see below). Most PBL implementations require students to follow a set of steps or a structured method of attacking problems (for example the Maastricht Seven Step method (Bloom et al., 1958), and SET was designed in the PBL tradition. The most important considerations that went into the design were simplicity (for students who had to go straight into PBL without a lengthy induction process), operational constraints (the sessions were short, busy, and conducted without shared computing facilities), and the desire to focus on linking preexisting knowledge into the PBL process. The first step was to divide a sheet of blank paper into three sections (Fig. 1); each of the three sections was marked with a letter:

$\mathrm{S}$ - Summarise the problem

E - Existing knowledge related to the problem

$\mathrm{T}$ - Things to find out to solve the problem

By working together on a short summary, each group member was required to focus on the problem by discussing it. In many cases there were a number of different things being asked of the group, and careful analysis of all

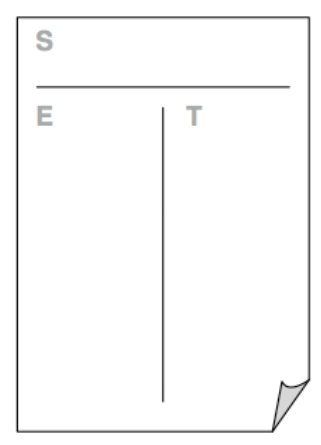

Fig. 1 The basic layout of an 'SET' sheet.

correspondence was required to define the nature of the problem clearly.

This summary step is a key element of the PBL process. Many groups showed a tendency to want to dive straight into the details of the problem, and facilitators needed to work with the groups to keep them focussed on clearly summarising the problem before progressing. These discussions often fostered a greater collective understanding of what was being asked in the problem, especially as quieter students gained the confidence to contribute to the discussion. In most cases this happened after a small number of sessions. When filling in the ' $E$ ' column, students catalogued their related existing knowledge. Given the range of backgrounds and abilities of the students, this column often contained a number of concepts that some group members had no knowledge of. It was the responsibility of the person with that specific knowledge to teach fellow group members about that concept before it could be added to the list. In order to tackle the problem effectively, groups had to get a clear idea of which concepts belonged in the ' $\mathrm{T}$ ' list. Students were told that they should aim to transfer all concepts originally placed in the ' $\mathrm{T}$ ' column into the ' $\mathrm{E}$ ' column before the second contact session by studying in their own time. Students were encouraged to spend a considerable amount of time in the first contact session working on the 'SET strategy', as it allowed the group to work together to get a clear picture of what the problem was and how they should approach it. Over the course of the semester some groups had a tendency to spend less time working on the strategy as they felt it would be more productive to start working directly on the problem. Due to the nature of the problems, groups adopting this approach often struggled to fully grasp what was being asked of them, and eventually had to resort to spending time discussing their existing knowledge at a later stage in the problem-solving process. In order to avoid overloading individual students, groups were advised to share the workload evenly at the end of the first session; students were told that they would have to brief their group-mates on what they had been working on at the start of the next session.

By the start of the second contact session students had spent time researching concepts from the ' $\mathrm{T}$ ' column and had transferred them into the ' $E$ ' column; the best prepared groups also arranged to meet in their free time to discuss how to 
apply their knowledge to the problem. The second session gave the students an opportunity to decide how best to apply their related knowledge to solving the problem. In the early stages of the semester it was common for groups to consult facilitators for assistance. It was initially difficult for students to grasp the fact that they were responsible for their own learning and that facilitators didn't have an ideal solution for the problem (often because one didn't exist). Facilitators were able to overcome these problems by engaging the groups in conversation about concepts related to the problem. Getting the group to describe the problem was often a good starting point, as the students gained a deeper understanding of the problem every time they discussed it. It was often found that students had a good understanding of the concepts, but had difficulty relating it to a real world scenario; students would also often need to revise the problem summary as their understanding of the problem improved, and the $\mathrm{E}$ and $\mathrm{T}$ columns were also continuously updated so that the strategy remained useful throughout the problem-solving process.

The groups that made good use of the 'SET strategy' left the second session with a clear idea of how to complete the problem. Students were told to complete each problem within a week (in order to ensure that they were only working on one problem at a time), and received feedback from facilitators via the University's VLE at the end of the week. Students were allowed to make further modifications based on the feedback they received until the end of the scenario (the end of the sixth week in the case of "A Tiny Adventure”).

\section{Use of the Virtual Learning Environment}

Problems were issued to students electronically (by email and on the VLE) the day before the first contact session. A wiki (an expandable and easily editable web page) was created on the VLE to accommodate the problems and related information. Students were asked to read through the problem before the first session; each group was given one printed copy of the problem in the contact session (due to lack of I.T. facilities in the locations used). By creating a wiki to deliver the problems to students, additional information could be made available including course announcements, general advice on how to tackle PBL problems as well as web links, podcasts, pdf study guides and lecture notes linked to the concepts covered in the problem. These resources could be updated by any of the facilitators if they found something relevant.

As well as the wiki containing all of the problems and resources, all groups had their own wiki which could only be accessed by members of that group and the teaching staff. All group deliverables were submitted on the wiki. The style of the wiki was decided by the group members themselves, and they had complete creative freedom to present their deliverables as they saw fit. The nature of the wikis allowed students to make as many revisions as they desired to their work. They were also free to leave comments at the bottom of the page if there was an issue to be raised, but they didn't want to change the actual content of the page. Facilitators made use of the comments feature to give the students feedback at the end of every problem. Based on experience from the i-Science degree, feedback was primarily used to help students deliver at the right level. This is of key importance in PBL, as open-ended problems often don't naturally provide good indicators of the level of response required, and the authenticity of problems can often be compromised if the nature of responses required are overspecified. Facilitators were able to track the modifications made to the wiki through a 'History' function available on the page. This function also revealed the identity of the contributors, but was not used to evaluate individual contributions, as some groups decided to give one member the responsibility of uploading all material to the wiki.

As well as accessing the problem and uploading their solution, the VLE made other vital contributions to the PBL component of this module. Each group was given basic communication tools, which allowed students to coordinate their off-campus contributions to solving the problems. Each group was given access to a group forum, a group email function and a file sharing tool. The groups that made best use of the forum between the contact sessions appeared to have made more progress when they spoke to the facilitators in the second session. The VLE was also used to allow the students to peer-assess each other. In order to ensure a fair distribution of marks throughout the group, each student was asked to rate every other member of their group. As well as ranking the contribution of each team member, students could give comments about the specific contributions of different group members. The peer assessment was performed three times throughout the semester to guarantee that any variations in performance were accounted for. As well as asking the students to peer-assess their group mates, they were given a report form on which they could submit any urgent comments related to the operation of the PBL component of the module; students were requested not to use this form to simply duplicate their responses to the peer review surveys.

\section{Staff training and facilitation}

In order to run the module effectively, six facilitators (two staff and four postgraduates) were used to guide the 84 students. Facilitators had to be careful not to lead the dicussion and hence direct the group towards a solution. Rather, their role was to coax students to discuss their current knowledge and hence identify gaps they needed to fill in order to explore possible solutions. Facilitators were advised not to provide answers to gaps in student knowledge. Occasionally facilitators would need to intervene if they felt a group was being distracted into a completely irrelevant area. The facilitators took a much less active role than tutors in traditional teaching scenarios (e.g. workshops and tutorials). Facilitator training has been shown to be effective at preparing facilitators for the challenges of a non-standard educational technique such as PBL (Duch, et al., 2001; Raine and Symons, 2005). Facilitators were trained prior to the start of the semester: this first session of training involved a short talk about the concepts of PBL, the role of the facilitator, and what problems they were likely to encounter. In the second training session the facilitators were shown how to use the virtual learning environment and its wiki function. In the final 
session the facilitators were given a sample PBL problem, and asked to work together on a solution. By working together on a solution to the problem, the facilitators were able to understand the process that the students would go through at the start of each problem session.

In order to assist the facilitation of the module, a facilitator wiki was created. This wiki could be accessed on the VLE by facilitators but not by students. The facilitator wiki was based upon the student version. In the facilitator version each problem was accompanied by a list of the learning objectives, a summary of the key concepts it was hoped students would cover in answering this problem, as well as some additional resources, comments and solutions (where applicable). Facilitators were able to leave comments on this wiki if they had any specific questions. The facilitators also had their own forum to discuss any issues related to the PBL component of the module.

Throughout the module the facilitators encountered a number of difficult situations. The most commonly encountered problem was students becoming 'stuck'. When this happened the facilitators found it useful to refer back to the SET sheet and ask the group to reconsider the relevance of their problem summary as it is likely they have based their solution on this summary. In a situation like this it can also be be useful to encourage students to brainstorm; sometimes this needs to be triggered by some ideas contributed by the facilitator. Another common problem is the fact that students are hesitant to make suggestions in the presence of the facilitator, as they are worried that they might be marked 'wrong'. The facilitator should reasure students that they are not there to evaluate everything that is said, the facilitator should act in a guiding role.

\section{Assessment}

Assessment of the PBL component of 'Chemical Principles' was conducted in two stages. The first problems to be assessed were the 'A Tiny Adventure' set of problems at the end of the first six weeks of the semester. The remaining three spectroscopy-based problems, along with an individual assignment, were assessed at the end of the semester. All facilitators contributed to the assessment process by assessing the work of the groups they were responsible for during the semester; a detailed mark scheme was provided for each problem to ensure that marking was consistent throughout the entire group. The six problems of the 'A Tiny Adventure' scenario were marked out of 30 ; the marking criteria varied for each problem, but were designed to assess the level of scientific content, the correctness and completeness of the answer and the style of writing and presentation. Deliverables for these problems were quite variable and included letters, explanations, calculations, presentations and functional Excel spreadsheets. The three problems based on Spectroscopy were also marked out of 30 . The deliverable for the first of these problems was a poster, marked according to modified criteria, which took into account the important considerations involved in preparing a scientific poster. The posters were displayed in a group poster session in which each student had the opportunity to vote for their three favourite posters. The creators of the three most popular posters were rewarded with prizes, but this did not contribute to the assessment of this task.

The group mark obtained for the nine weekly problems were weighted for each group member. This weighting was based on the comments of facilitators, responses to the peerreview surveys and the attendance record of the student in question. If the student made an outstanding contribution to group work throughout the semester a scaling factor of 1.1 was used. If the contribution of the student was significantly less than that of other members the mark was scaled by a factor of 0.9 , students who made particularly weak contributions had their individual mark scaled by 0.7 . These scaling factors were only used when there was overwhelming justification for it (by considering all the factors mentioned above) and all other marks were unscaled. Although the precise scaling applied was not explicitly given to students when marks were released, this information was available to them by enquiry from that point on. In addition, it was clearly indicated to all students from the outset that their individual marks would be obtained by scaling the group marks according to their level of involvement. The scaled mark for group work contributed $80 \%$ of the individual's final PBL mark, the remaining $20 \%$ being awarded for an individual assignment. This was a short essay writing exercise, The students were asked to write a scientific critique of the movie script for the "A Tiny Adventure" section of the module.

Due to the nature of PBL activitites, students gain more transferable skills experience than in the previous, lecture and workshop based, version of the module. Learning outcomes have been revised to reflect the development of teamwork skills such as organization and (in some cases) leadership, enhanced communication (both written and oral) skills and a greater range of IT skills.

\section{Evaluation}

\section{Results and student retention}

PBL activities were evaluated using a variety of techniques, including independent interviews (with both staff and students), comparison of student performance in exams and Multiple Choice Question (MCQ) Tests with results from previous years, and a collection of observations recorded by the facilitators.

Student performance was recorded in the 'Chemical Principles' exam, MCQ tests and the overall module mark. The comparison of exam and module marks in 'Chemical Principles' and another level 1 Inorganic module are presented in Table 1.

The overall conclusion drawn from comparing the module and exam average marks is that the introduction of PBL teaching has had no adverse effect on student performance. The average mark for both the 'Chemical Principles' module and exam in the 2007/08 academic year fall between the highest and lowest marks for the previous three academic years. The average performance of students in each year group since 2005 hasn't varied greatly; this is supported by student performance in the 'Coordination Chemistry' module, which 
Table 1 Comparison of the exam and module marks in the 'Chemical Principles' and 'Coordination Chemistry' modules between 2005 and 2008

\begin{tabular}{ccccc}
\hline Year & $\begin{array}{c}\text { Chemical } \\
\text { Principles } \\
\text { Exam } \\
\text { Average }\end{array}$ & $\begin{array}{c}\text { Chemical } \\
\text { Principles } \\
\text { Module } \\
\text { Average }^{\mathrm{a}}\end{array}$ & $\begin{array}{c}\text { Coordination } \\
\text { Chemistry } \\
\text { Exam } \\
\text { Average }\end{array}$ & $\begin{array}{c}\text { Coordination } \\
\text { Chemistry } \\
\text { Module } \\
\text { Average }^{\mathrm{d}}\end{array}$ \\
\hline 2008 & 49 & $54^{\mathrm{b}}(54)^{\mathrm{c}}$ & 62 & 63 \\
2007 & 54 & 58 & 60 & 63 \\
2006 & 58 & 62 & 55 & 58 \\
2005 & 45 & 50 & 62 & 63
\end{tabular}

a - Chemical Principles module mark (except 2007/08): 70\% exam, 15\% tutorials, $15 \%$ class tests

b - Chemical Principles 2007/08 module mark: 60\% exam, 10\% tutorials, $15 \%$ class tests, $15 \%$ PBL

c - Average for PBL component (15\% contribution to module average)

d - Coordination chemistry module marks: $80 \%$ exam, $10 \%$ tutorials,

$10 \%$ course test.

Table 2 Comparison of student performance in Multiple Choice Question (MCQ) tests issued throughout the semester between 2004/05 and $2007 / 08$

\begin{tabular}{lcccc}
\hline Test 1 & $\begin{array}{c}\text { Number of } \\
\text { students }\end{array}$ & $\begin{array}{c}\text { Lowest } \\
\text { mark }\end{array}$ & $\begin{array}{c}\text { Highest } \\
\text { mark }\end{array}$ & Average/20 \\
\hline Oct 2007 & 84 & 7.8 & 20 & 14.7 \\
Oct 2006 & 60 & 6.3 & 20 & 14.9 \\
Nov 2005 & 57 & 5.6 & 19 & 14.3 \\
Nov 2004 & 57 & 5 & 19 & 14.1 \\
\hline Test 2 & & & & \\
\hline Dec 2007 & 83 & 5 & 20 & 11.8 \\
Dec 2006 & 59 & 6 & 17 & 11.2 \\
Dec 2005 & 52 & 6.5 & 20 & 11.5 \\
Dec 2004 & 53 & 3 & 19 & 11.5 \\
& & & & \\
\hline
\end{tabular}

has a similar level of consistency. The PBL average mark was $54 \%$, the same as the overall module average, though slightly higher than the exam component (49\%). The exam mark range was $12-79 \%$, whilst the PBL range was $28-91 \%$. The slightly higher marks for PBL may be because group work makes a contribution and it does not involve memorising.

Table 2 provides a comparison of the performance of students in the 'Chemical Principles' MCQ tests, which were issued throughout the semester. As in the comparison of final exam and module marks, this table also shows that the reduction in the number of lectures and their replacement with PBL did not have an adverse effect on student performance. Thus, the overall average in Test 1 is within the limits of those of the previous 3 years. The 2007/08 averages also apply to a much bigger cohort than the previous 3 years. The average mark for test 2 in 2007/08 was the highest by a small margin over the same period.

Another significant observation from the test results is that only one student dropped out of the course between October and December. Given the very high intake in this academic year it might have been expected that the number of students dropping out through the first semester would be significantly higher. Our student feedback (see below) shows that the group work involved in PBL helped them make friends early in the term. We feel that this is certainly a significant contributing factor in the low drop out numbers. Further evidence of the social impact was seen when PBL groups were observed attending lectures, workshops and Chemsoc social events together, which seems to indicate that the PBL was effective in integrating students into university life. Indeed, many students reported to tutors that being assigned to a PBL group on arrival had provided them with an instant social circle and an easy route to getting to know other students. In some cases students commented that they had made very good friends with people they almost certainly wouldn't have spoken to under other circumstances.

\section{Feedback}

To help assess the impact of PBL, independent interviews were conducted by the Centre for Recording Achievement in two separate visits to the department. Students were interviewed at the end of term, staff and postgraduate facilitators were interviewed six months later, at the end of the academic year.

Student feedback. The findings from the interviews were compiled in a report (Nijjar and Ward, 2008), the findings from which are summarised here. The responses given by the students indicate that there was a range of opinions on the use of PBL in the Chemical Principles module. Students suggested a number of motivations for using PBL, and showed an appreciation of factors such as "the ability to apply scientific knowledge to everyday situations" and the fact that PBL "teaches you to work in a group with different group members", which were both felt to be important for their future careers. Students also appreciated the use of a different learning method that required them to consider the subject in a different way, "It helps you to think differently; it's about applying rather than just learning”. Some students criticised the Hollywood style movie script aspect of the scenario, as it was felt that this often obscured the PBL problems rather than making them fun and accessible. The second set of problems, which was based on self-contained scenarios, was praised by some students, one of whom commented "this felt good ... it was for something”. The first scenario dealt primarily with more abstract concepts than the rather applied spectroscopic ideas from the second set of problems. The movie studio vehicle was key to providing a real-world type hook for the topics, which often do not lend themselves to typical PBL problem formats, but it is not surprising that students felt more comfortable with the later problems which tended to use real world data and consisted of genuinely relevant problems, for example, a spectroscopy based problem in which students identified ingredients from a soft drink using a number of different spectroscopic techniques, and developed a technique to measure water depth spectroscopically.

There were a variety of opinions on the PBL approach to learning. Some students welcomed an alternative teaching technique that allowed them to "get involved", and many students also identified the personal and social benefits in that it helped them get to know a number of people on the course at an early stage in their education. This sentiment was also strongly expressed by the staff. The opportunity to work 
within a group environment was welcomed by some students one of whom stated that PBL "Teaches you to work in a group with different group members"; another said that the process "mimics industry". However, a minority of students didn't see the value of working in a group and preferred to work alone; others reported that it was frustrating when their groups didn't 'gel'. One student in particular had difficulty working in a group. The student didn't want to divide responsibility for solving the problem with fellow group members. After discussing problems with members of staff and developing a closer working relationship with fellow group members the student became a highly productive and motivated contributor to the group's work.

Another issue raised by students was the sequencing of problems. Some students felt that it would have been useful to have PBL sessions following lecture which introduced the basic concepts, which didn't always happen. In surprising contrast, however, other students appreciated the opportunity to do some research on a subject before it was introduced to them in a lecture. This highlights the very different learning styles that students have and provides evidence in the argument for adopting blended learning (Garrison and Kanuka, 2004). We mixed PBL with conventional teaching for this reason.

There were some issues related to scheduling. The student view was that only a limited amount of time needed to be spent dividing the tasks with each person then researching what they thought they already knew, i.e. "play to our existing strengths". Hence, after a quick allocation of topics they could then immediately start researching them. There were some problems with this approach on a practical level, since wireless internet access was available in only one of the two rooms used. Although textbooks were provided in both locations, students were more reluctant to use these for researching a topic. In contrast, the staff view was rather different, with staff encouraging a full exploration of existing knowledge and understanding within the groups, prior to allocation of tasks. Whilst some students conceded that "sometimes it was good to think together about the problem", they found this a difficult task, with many groups tending to rely on the facilitator to question what they really knew and their level of understanding of that knowledge. There were also some issues in busy weeks with students not being able to complete their tasks prior to the second session, hence the opportunity for pooling knowledge and learning from the work of others was sometimes felt not to be working out effectively.

Some students commented on the transferable 'soft' skills that were developed through the process; students referred to time management and communication skills, other students commented that it was difficult to develop these skills in the time available to them. The potential benefits in future employment featured prominently in the feedback received from students; some students believed that the rationale for using PBL was sound as "Companies like people who can solve problems"; one student also commented that "It helps you to think differently; it's about applying rather than just learning”.
The feedback received from students was highly valuable, as it showed that a range of opinions exist on the effectiveness of the techniques as a whole, as well as providing information on several specific aspects of implementation. The feedback received from the 2007/08 group is being used to modify the delivery of PBL in future courses in the Department of Chemistry. One example of these modifications is the introduction of group rotation, which was subsequently used in a foundation year module later in the same academic year. When group rotation is used the students are assigned to groups for a fixed period of time, when the problems from that period of time have been completed students are moved into different groups; this allows students to work with people from a wider range of backgrounds, and possibly identify different roles for themselves in the different group arrangements.

Staff feedback. At the end of the academic year a second series of interviews was conducted with staff and postgraduate facilitators involved in the implementation of PBL. The overall impression from the staff is that the introduction of PBL to the department has been successful. One interviewee commented "PBL has been embedded here, it's not just a pilot, and that's quite a rapid embedding”. The impression gained from these interviews was that the department is ready to extend the use of PBL further. Staff interviews confirmed the previously recorded observation that students appear to interact socially with the other members of their group, which has a positive impact particularly on group work in tutorials, and workshop sessions, as well as a possible benefit to student retention.

\section{Conclusions}

Overall, the introduction of PBL to the Department of Chemistry at the University of Leicester has been judged a success, From an academic viewpoint the success of students in the conventional tests has been relatively unaffected. However, the staff and many of the students feel that some of their transferable skills, including communication, organisation and particularly team working, were improved. Using PBL in the first term of the first year has been particularly successful in helping students make friends, which can be critical to their early success at university. We believe this also was a factor in the improved student attitude to learning in our conventional workshops, and also contributed to the fact that no one left the course in the first term. This social benefit was rather unexpected, but provides a good reason to use PBL early in a course.

\section{Appendix}

\section{Example problem}

Overview. The first problem in the 'A Tiny Adventure' scenario (inspired by the film 'Fantastic Voyage') was called 'Size and Scale'. This problem was introduced to the students by a letter (see Fig. 2) received from the studio, which was made available electronically. The basis of the problem was 
Dear scientific advisory team,

Welcome to our production team!

As you might have already gathered from the minutes of the meeting we had last week (see next page) here at Imperial Studios, it was noted that it would be a good starting point if you could prepare a list of some of the various structures the ship is likely to encounter during the "journey" and give an idea of their sizes. We would like to use a 'magnification meter' in the movie as part of the ships' view screen. We think this scenario opens up many possibilities; we would love to know how small the ship would have to be before the crew could see the nucleus of an atom or even its electrons!

This might sound like a simple task, but there's a bit more to it than meets the eye! Our chief animator, David Harlan, has suggested that you prepare an interactive spreadsheet, using Microsoft Excel. According to David, Microsoft Excel is a very powerful tool and it is easier for him to use than having to resort to working everything out off a written list! The idea is he would like a spreadsheet that contains all the different structures and their absolute dimensions (approximate diameters and volumes). He also would like the spreadsheet to be interactive such that by entering the desired magnification level, he can instantly find out the size of objects as the crew would see them - e.g. would they appear to be the size of a coin, a football or a house?

To make things easier for you we have decided to have a series of fixed magnification levels e.g. 1000 , 10000 etc. The spreadsheet should not contain more than 8 structures. The types of structure we're really interested in include nuclei, atoms, amino acids, proteins and maybe blood cells! I'm sure we can create some amazing scenes where the ship is bombarded by a fleet of massive red blood cells or even barraged by a stream of football sized electrons. We need your help to get an idea of the scales involved. Please find David's specifications along with the minutes from our last meeting on the next page.

Yours sincerely,

Nicola Paige

Nicola Paige, Producer

Fig. 2 Example of a communication received by students as part of the 'Size and Scale' problem.

that the 'studio' wanted the students to create an interactive spreadsheet that the animator would be able to manipulate to get an idea of the scale of the structures the ship would encounter in the body, and how big these objects were relative to the size of the ship. This was the first experience of PBL for most students, so the early stages of the problem solving process were emphasised in order to ensure that students became accustomed to the strategy for solving such problems. This was achieved by scheduling an introductory lecture in the week of the problem release and by asking facilitators to ensure that students followed the problem solving strategy described in the lecture.

The learning outcomes for this problem (Fig. 3) were designed to complement the material covered in both the CH1000 lectures and the maths workshops. In the lectures students were being introduced to concepts including subatomic particles, atoms and molecules, so it was useful to encourage students to consider the relative and absolute sizes of these structures in the form of a PBL problem.

Implementation of 'Size and Scale' in the classroom. Groups were asked to read through the problem before the session and bring printouts of the letter to the session. At the start of the first session students were asked to discuss their understanding of the problem with the rest of their group, and to produce a short summary of the problem. The remainder of the first session was used to plan a solution to the problem using the 'SET' strategy. During this session the facilitator encouraged students to discuss concepts such as relative and absolute scale, units, factors of magnification, conversion between 2-D and 3-D quantities (i.e. $\mathrm{mm}^{2}$ to $\mathrm{m}^{2}$ ), etc. Students identified which of these concepts they needed to research further, and ended the session by dividing responsibility for researching these concepts amongst the group.

When implementing this problem it was useful to have a supply of general chemistry textbooks that students can use to get an idea of the dimensions of some of the structures that they expect the ship to encounter in the body.

Facilitation of 'Size and Scale'. Facilitation of this problem involved two contact sessions (one hour each) and reading through student work on the VLE in order to provide formative feedback.

For the 'Size and Scale' problem, each facilitator worked with either two or three groups of students. During contact sessions facilitators circulated between their groups, dividing their time between the groups according to the level of progress shown by each group.

One key problem that occurred during the first session was that some students were reluctant to engage in a dialogue with the rest of the group. In order to ease the transition to studentcentred learning (this problem was tackled at the start of the first semester of the first year), facilitators were advised to start the first session with a short icebreaker activity. Students were asked to introduce themselves by playing 'Alliterative Introductions**; it was found that this was an effective way of removing the tension from the situation and allowing students to initiate contact with their group mates. 


\section{Learning objectives}

Scientific skills

By the end of the problem all students should:

- be familiar with the size scales of molecules, atoms and biological structures, and to relate these to the size of everyday objects;

- be able to convert units (i.e. $\mathrm{nm}$ or $\mathrm{mm}$ to $\mathrm{m}, \mathrm{dm}^{3}$ to $\mathrm{m}^{3}$, etc.) and know what magnitude prefixes correspond to (e.g. nano $\left.=1 \times 10^{-9}\right)$;

- be able to prepare an Excel spreadsheet to interpret results (and become more familiar with many of the programme's functions);

- be able to determine volumes and areas of structures from absolute dimensions.

\section{Transferable skills}

By the end of the problem all students should:

- be able to work with others to thoroughly plan a solution to a problem by identifying the nature of the problem, identifying related knowledge and identifying learning issues that must be resolved to solve the problem;

- have gained experience of maximising group efficiency by helping to research a specific part of the problem and then feeding back to the rest of the group;

- be capable of producing a professional response;

- be able to gauge the level of content of their reports for the particular audience that will be reading it.

Fig. 3 Learning objectives for the 'Size and Scale' topic.

\section{Assessment}

The output of this activity took the form of an interactive spreadsheet, which included the absolute size of a number of microscopic (and smaller) structures, a simple way of determining the apparent size of these structures at a number of magnification levels and the size of these structures relative to a number of given macroscopic objects at each magnification level. Students were also asked to provide a set of clear instructions for the use of this spreadsheet, which was a useful way of testing how well the group understood the unctionality of their own work.

Responses received from the students varied from simple spreadsheets that required the user to input some of the values manually, to complex, multi-sheet spreadsheets that automatically calculated the apparent and relative sizes when the user selected the magnification level from a drop down menu.

Alongside the production of the spreadsheet, students were asked to produce a short written justification of the structures that they chose to include on their spreadsheet. This was a useful way of getting students to read more about some of the strcutures they had been introduced to in CH1000 lectures (i.e. electrons, protons, atoms, molecules, etc.) and gave facilitators a chance to encourage the students to expand their understanding by asking some targeted questions during the facilitation sessions (e.g. how many atoms can fit onto a pin head?, which illustrated some of the more abstract concepts covered in the module.

The assessment was carried out using the procedure described in the assessment section; feedback was given to the students in the first instance, followed by a period of time when the students could make ammendments to their work. A second deadline was set at which point the work would be summatively marked.

\section{Notes and References}

I University of Leicester, Centre for Interdisciplinary Science (www.le.ac.uk/i-science) (Accessed 2009)

‡ Chemistry for our Future, Royal Society of Chemistry http://www.rsc.org/Education/CFOF/ (Accessed 2009)

* Aliterative introduction is an 'icebreaker' activity in which a group member introduces themselves with an alliterative sentence. The activity continues by moving around the group with the following member introducing themselves with an alliterative sentence in addition to repeating all previous introduction. http://improvencyclopedia.org/games//Alliteration_Introduction.html

Albanese M. A. and Mitchell S., (1993), Problem based learning: a review of literature on its outcomes and implementation issues, Academic Medicine, 68, 52-81.

Andraos J., (1999), J. Chem. Educ., 76, 1578-1583.

Barrows H. S. and Tamblyn R. W., (1986), A Taxonomy of problem based learning methods, Med. Educ., 20, 481-486

Belt S. T., Enas H. E., McCreedy T., Overton T. L. and Summerfield S., (2002), Univ. Chem. Educ., 6, 65-78.

Bloom B. S., Mesia B. B., Krathwohl D. R., (1964), Taxonomy of educational objectives New York.

Blumenfeld P. C., Soloway C., Marx W. M., Krajcik J. S., Guzdial M. and Palincsar A., (1991), Motivating problem based learning: sustaining the doing, supporting the learning, Educ Psychol, 26, 369398.

Boud D. and Felletti G. E., (1997), The challenge of problem-based learning, Kogan-Page London.

Bredderman T. (1983), Effects of Activity-based Elementary Science on Student Outcomes: A Quantitative Synthesis, Rev. Educ. Res., 53, 499-518

Duch B.J., Groh S.E. and Allen D.E., (2001), The Power of Problem Based Learning, Stylus Publishing, Sterling, Virginia

Engel C. E., (1997), Not just a method of learning but a way of learning, in: Boud D, Feletti G. E. eds. The challenge of problem based learning. London: Kogan Page.

Garrison D. R. and Kanuka H. (2004), Blended learning: uncovering its transformative potential in higher education, The Internet and Higher Education, 7, 95-105.

Harris J., Hendry H. and Ryan G., (1996), Group problems in problembased learning, Med. Teach., 25, 609-616.

Heycox K., Bolzan N., (1991), Applying problem-based learning in first year social work, in: Boud D, Feletti G. E. eds. The challenge of problem-based learning. London: Kogan Page.

Nijjar A. and Ward R., (2008), Formative evaluation of strand 3.2 of 'Chemistry for our future'; Context and PBL in Chemistry, Centre for Recording Achievement. (http://www.rsc.org/Education/CFOF/DevelopingHECurr/Chemistry 4all.asp)

Raine D. and Symons S., (2005), PossiBiLities: a practice guide to problem-based learning in physics and astronomy, The Higher Education Academy - Physical Sciences Centre (http://www.heacademy.ac.uk/assets/ps/documents/practice guides/p s0080 possibilities problem based learning in physics and astron omy mar 2005.pdf)

Rhem J., (1998), Problem based learning: an introduction. NTLF (www.ntlf.com), 8, 1 
Ryan G., (1997), Ensuring that students develop an adequate, and wellstructured, knowledge base, In: Boud, D, Feletti, G.E. eds. The challenge of problem based learning.

Walker S., (2009), in Student retention and widening participation, Physical Sciences Centre, Higher Education Academy (http://www.heacademy.ac.uk/assets/ps/documents/toolkits/toolkits/st udent retention_widening_participation_2009.pdf

Accessed September 2009).

Woods D. R., (1996), in Problem-based learning: helping your students gain the most from PBL, McMaster University, Hamilton (http://chemeng.mcmaster.ca/pbl/pbl.htm Accessed 2009). 